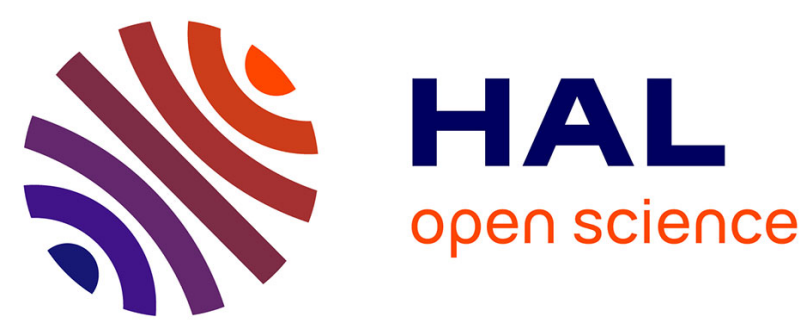

\title{
Aqueous Dispersions of Nonspherical Polyethylene Nanoparticles from Free-Radical Polymerization under Mild Conditions
}

Etienne Grau, Pierre-Yves Dugas, Jean-Pierre Broyer, Christophe Boisson, Roger Spitz, Vincent Monteil

\section{To cite this version:}

Etienne Grau, Pierre-Yves Dugas, Jean-Pierre Broyer, Christophe Boisson, Roger Spitz, et al.. Aqueous Dispersions of Nonspherical Polyethylene Nanoparticles from Free-Radical Polymerization under Mild Conditions. Angewandte Chemie International Edition, 2010, 49 (38), pp.6810-6812. 10.1002/anie.201001800 . hal-00948692

\section{HAL Id: hal-00948692 \\ https://hal.science/hal-00948692}

Submitted on 20 Nov 2019

HAL is a multi-disciplinary open access archive for the deposit and dissemination of scientific research documents, whether they are published or not. The documents may come from teaching and research institutions in France or abroad, or from public or private research centers.
L'archive ouverte pluridisciplinaire $\mathbf{H A L}$, est destinée au dépôt et à la diffusion de documents scientifiques de niveau recherche, publiés ou non, émanant des établissements d'enseignement et de recherche français ou étrangers, des laboratoires publics ou privés. 


\title{
Aqueous Dispersions of Non Spherical Polyethylene Nanoparticles from Free Radical Polymerization under Mild Conditions**
}

\author{
Etienne Grau, Pierre-Yves Dugas, Jean-Pierre Broyer, Christophe Boisson, Roger Spitz, and Vincent \\ Monteil*
}

Polyethylene, the first manufactured polymer by volume, is usually synthesized from low pressure and temperature catalytic processes $^{[1,2]}$ or a high temperature $\left(>200^{\circ} \mathrm{C}\right)$ and pressure (> 1000 bar), highly energy consuming free-radical polymerization process. ${ }^{[3-5]}$ In the latter case a branched, low density, polyethylene is produced (LDPE) in contrast to Ziegler Natta catalysis which enables the synthesis of high density polyethylene (HDPE) exhibiting higher crystallinities and melting temperatures. These well established polymerization processes require improvement: reduction of energy consumption and/or Volatile Organic Compounds (VOC) are important targets. The VOC issue has been greatly solved for low pressure catalytic Ziegler-Natta polymerizations by using solvent-free gas-phase processes. For slurry polymerization new catalysts compatible with "green" diluents such as supercritical $\mathrm{CO}_{2}^{[6,7]}$ or water ${ }^{[8-11]}$ have been developed recently.

Recently we successfully produced polyethylene (PE) by a radical pathway under less energy consuming conditions: medium pressure $<250$ bar and low temperature $70^{\circ} \mathrm{C}$ using organic solvents (toluene or THF). ${ }^{[12]} \mathrm{PE}$ was synthesized in high yields and exhibited intermediate melting points and crystallinities in comparison to $\mathrm{HDPE}$ and $\mathrm{LDPE}\left(115^{\circ} \mathrm{C}<\mathrm{Tm}<119^{\circ} \mathrm{C}\right.$; crystallinity of $55-70 \%$ ). However, polymer molecular weights remained low $(\mathrm{Mn}<5000 \mathrm{~g} / \mathrm{mol}, \mathrm{PDI} \approx 2)$ because of frequent transfer reactions to the solvent.

Transposition to an emulsion polymerization in aqueous dispersed medium (benefiting from the compartmentalization of radicals and from the low transfer ability of water) should be useful to increase both molecular weight and yield and at the same time to solve the VOC issue.

Only few works on free radical polymerizations (FRP) of ethylene in aqueous dispersed media have been reported ${ }^{[13-17]}$ at relatively high pressures $(\mathrm{P}>300$ bar) and a wide range of temperatures. The interpretation of the results in these early works (from 1945 to 1975) is not easy because of the lack of analytical tools to study colloidal properties of the polymer dispersions

[*] E. Grau, P.-Y. Dugas, J.-P. Broyer, Dr. C. Boisson, Dr. R. Spitz, Dr. V. Monteil

UMR 5265 Laboratoire de Chimie Catalyse Polymères et Procédés (C2P2), LCPP team

Université de Lyon, Univ. Lyon 1, CPE Lyon, CNRS

Bat 308F, 43 Bd du 11 novembre 1918, 69616

Villeurbanne, France

Fax: (+) 33472431768

E-mail: monteil@Icpp.cpe.fr

[**] E.G. thanks the "Ministère de la Recherche et de l'Enseignement Supérieur" for his fellowship. The authors thank Mettler-Toledo for the thermal analysis. We are indebted to $\mathrm{Mr} \mathrm{C}$. Graillat and Prof. B. Charleux for their valuable contributions to this research obtained.

Note that the emulsion process for ethylene polymerization can not be a classical one. Ethylene is a supercritical gas and consequently no ethylene droplets exist during the polymerization and no liquid unreacted monomer can remain in the latex. In addition PE is a crystalline material contrary to most conventional polymers produced by FRP.

In the present paper, FRP of ethylene in emulsion under mild conditions has been investigated, representing an innovative low energy consuming "green" efficient way to produce PE by a free radical mechanism. The transposition of ethylene polymerization process to aqueous medium has been achieved by using a cationic water soluble initiator, 2,2-azobis(2-amidinopropane)dihydrochloride (AIBA). FRP of ethylene was performed in water at $70^{\circ} \mathrm{C}$ with and without a standard cationic surfactant (CTAB, CetylTrimethylAmmonium Bromide) to assist nucleation and particle stabilization. In all cases ethylene was polymerized with significant yields and stable dispersions of PE particles were obtained for ethylene pressure up to 250 bar (Figure 1). Interestingly, PE can be synthesized by this FRP process down to 50 bar of pressure.

In the surfactant-free system, yield is lower than that obtained using the same amount of initiator in THF but higher than in toluene. ${ }^{[12]}$ The stabilization of PE particles is assumed to result from the cationic fragments of the initiator attached at the chain end which induce electrostatic repulsion. Average particles diameters (Dp) measured by DLS (dynamic light scattering) increase with the ethylene pressure (and consequently with the yield) from $30 \mathrm{~nm}$ to $110 \mathrm{~nm}$. Polydispersity indexes remain very low $(\mathrm{PI} \sim 0.05)$ indicating the monodisperse character of particle size distribution. In addition, the yield/ $\mathrm{D}_{\mathrm{p}}{ }^{3}$ ratio, standing for the number of particles, remains constant whatever the ethylene pressure.

When polymerizations were performed in the presence of a standard cationic surfactant $(\mathrm{CTAB})$ at $1 \mathrm{~g} / \mathrm{L}$ (above the critical micelle concentration: $0.2 \mathrm{~g} / \mathrm{L}$ at $25^{\circ} \mathrm{C}$ ), much higher activities were observed (Figure 1). This emulsion system is even more efficient than the polymerization in THF. ${ }^{[12]}$ In these non-optimized conditions, up to $40 \%$ of solid content are obtained (after degassing the 250 bar of ethylene). Average particle diameters seem to reach a plateau at $50 \mathrm{~nm}$ when increasing ethylene pressure. This indicates that the number of particles increases with the yield. Polydispersity indexes measured by DLS remain suprisingly higher $(\mathrm{PI} \sim 0.5)$ than for the surfactant-free process.

The PE produced exhibits a low melting point $\left(\mathrm{Tm} \sim 100^{\circ} \mathrm{C}\right)$ and low crystallinity (30-40\%). Highest values were obtained in the case of the surfactant-free polymerization process (see Supporting Information Table S1). As expected high molecular weights PE (Mn from $10^{4}$ up to $10^{5} \mathrm{~g} / \mathrm{mol}$ ) were produced. The number of PE chains synthesized is greater with CTAB indicating a possible transfer to surfactant (Supporting Information Figure S1). The PE obtained are moderately branched under both conditions (Figure S1: 30 branches/1000C without surfactant and 37 branches/1000C with $\mathrm{CTAB}$ ) as determined by ${ }^{13} \mathrm{C} \mathrm{NMR}^{[18]}$ which is in agreement with the crystallinities and melting temperatures measured. This higher branching level in water than in an organic solvent (THF: 
9 branches/1000C or Toluene: 7 branches/1000C) $)^{[12]}$ can be explained by the compartmentalization of the PE growing chains which increases transfer reactions to the polymer. The proportion of short chain branches is lower in emulsion $(25 \%$ vs $35 \%$ in organic solvent) due to favored intermolecular over intramolecular transfer reactions in a confined environment.

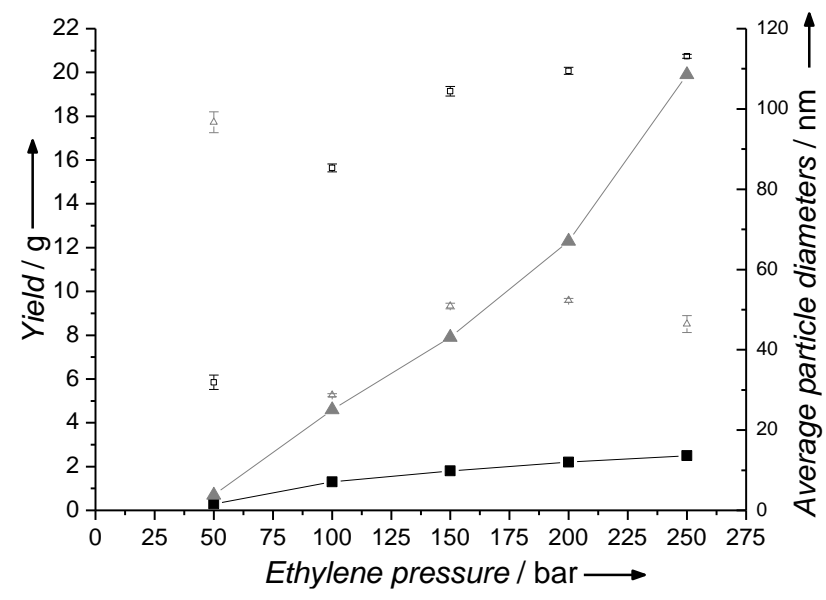

Figure 1. Free radical polymerization of ethylene in aqueous dispersed medium: - $\mathbf{-}$ yield and $\boldsymbol{\square}$ average particle diameter ${ }^{*}$ vs ethylene pressure $\left(80 \mathrm{mg}\right.$ AIBA, $50 \mathrm{~mL}$ water, $4 \mathrm{~h}$ at $70^{\circ} \mathrm{C}$ under ethylene pressure); $-\Delta-$ yield and $\Delta$ average particle diameter ${ }^{*}$ vs ethylene pressure $(80 \mathrm{mg}$ AIBA, $50 \mathrm{~mL}$ water with $1 \mathrm{~g} / \mathrm{L}$ of CTAB, $4 \mathrm{~h}$ at $70^{\circ} \mathrm{C}$ under ethylene pressure), ${ }^{*}$ determined by DLS

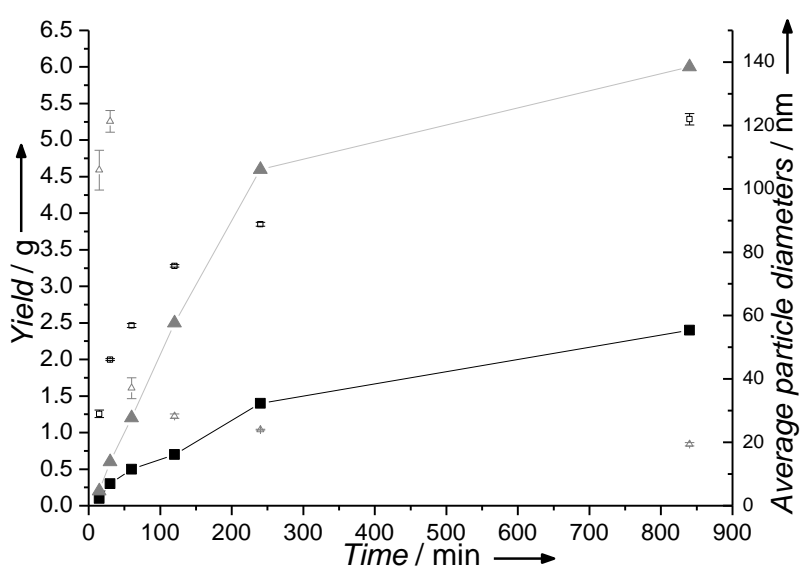

Figure 2. Reaction profile for of free radical polymerization of ethylene in aqueous dispersed medium: - $\mathbf{-}$-yield and $\mathbf{\square}$ - average particle diameter ${ }^{*}$ vs time $\left(80 \mathrm{mg}\right.$ AIBA, $50 \mathrm{~mL}$ water at $70^{\circ} \mathrm{C}$ under $100 \mathrm{bar}$ ); $-\Delta-$ yield and $\triangle$ average particle diameter ${ }^{*}$ vs time $(80 \mathrm{mg}$ AIBA, $50 \mathrm{~mL}$ water with $1 \mathrm{~g} / \mathrm{L}$ of $\mathrm{CTAB}$ at $70^{\circ} \mathrm{C}$ under $100 \mathrm{bar}$ ), * determined by DLS

In order to link solvent and emulsion processes, the influence of addition of organic solvents to water (water-miscible (THF) or nonmiscible (toluene)) was investigated. PE molecular weights dropped in the presence of solvents (see supporting information Table S2). $\mathrm{Mn}$ dropped from $50500 \mathrm{~g} / \mathrm{mol}$ in water to $8300 \mathrm{~g} / \mathrm{mol}$ and $2350 \mathrm{~g} / \mathrm{mol}$ for toluene $/ \mathrm{H}_{2} \mathrm{O}$ (1/4) and $\mathrm{THF} / \mathrm{H}_{2} \mathrm{O}$ mixtures respectively in the presence of CTAB. This decrease can be related to an increased frequency of transfer reactions to solvent (contrary to water, THF and toluene exhibit high transfer abilities) ${ }^{[12]}$ which has been confirmed by NMR analysis (see supporting information Figure S2). With THF, the transfer reaction should take place in the continuous aqueous phase or at the particle surface and not in the particles, because THF is not an efficient swelling agent for amorphous PE (same Dp is observed before and after removal of THF by partial reduced pressure evaporation). For toluene, the Dp drops by about $10 \mathrm{~nm}$ by removing the organic solvent (toluene is a swelling solvent for PE) so transfer could additionally take place inside the particles.

Surfactant-free and classical emulsion polymerization processes were compared by investigating the reaction profile at $70^{\circ} \mathrm{C}$ under 100 bar of ethylene (Figure 2). For the surfactant-free system, particle diameters increase with yield and the yield/ $\mathrm{D}_{\mathrm{p}}{ }^{3}$ ratio remains constant, thus no renucleation or aggregation took place during the polymerization.

In the presence of CTAB the behavior is quite different. Initially particles with large diameters are formed and seem to disappear with time to generate only small particles $(D p \approx 30 \mathrm{~nm})$ after $2 \mathrm{~h}$. The mechanism for the extinction of large particles to generate very small particles still remains unknown, but preliminary experimental results suggest a primordial role of the surfactant itself. For example if $1 \mathrm{~g} / \mathrm{L}$ of CTAB is added to surfactant-free PE latex, after stirring at $70^{\circ} \mathrm{C}$ small particles are ejected (see supporting information Figure $\mathrm{S} 3)$.

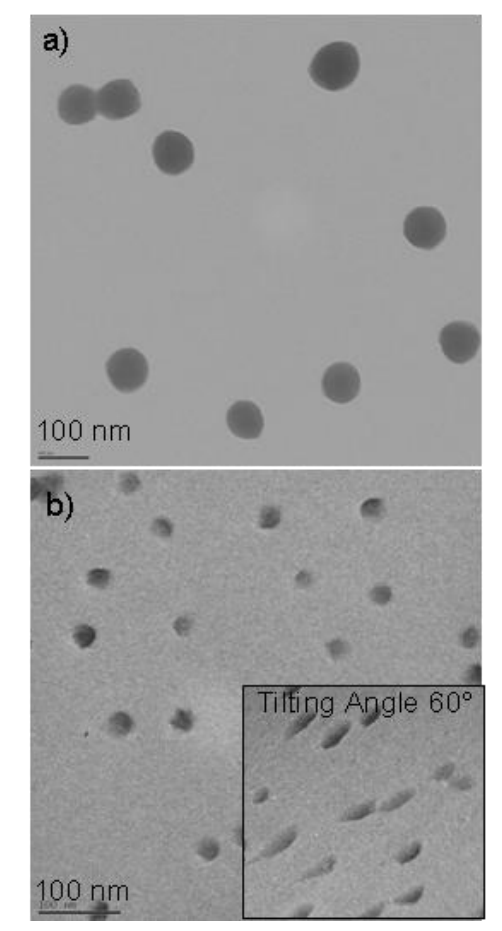

Figure 3. TEM pictures of $P E$ latex: a) standard particles without CTAB, 100 bar, $4 \mathrm{~h}$ at $70^{\circ} \mathrm{C}$ b) standard particles with $1 \mathrm{~g} / \mathrm{L} \mathrm{CTAB}$ (included with a tilting angle of $60^{\circ}$ ), 100 bar, $4 \mathrm{~h}$ at $70^{\circ} \mathrm{C}$.

The PE latexes were also characterized using TEM analysis (Figure 3). In the surfactant-free process quasi-spherical particles were observed. The rigid lamellas of semi-crystalline PE prevent the formation of spheres (as already observed for latex prepared by catalytic emulsion polymerization). ${ }^{[19]}$ Nevertheless, particles show a relative diameter homogeneity which is in agreement with DLS measurements (low PI).

In the presence of CTAB, TEM pictures show a low contrast for the surface of particles which could originate from flat particles. This has been confirmed by tilting the sample since disks were observed at $0^{\circ}$ and ellipses at $60^{\circ}$. Note that no significant changes were observed during tilt with PE latex obtained from surfactant free 
polymerization. From the hypothesis of cylinder-like particles, the dimensions of these objects were estimated (average disks diameters about $35 \mathrm{~nm}$ and thickness about 3-4 nm). From these findings we can better explain the high values of PI $(\sim 0.5)$ obtained by DLS (autocorrelation function of DLS being calculated for a size distribution of spherical particles) which were not in agreement with the apparent homogeneity in the diameters of particle sizes observed by TEM. ${ }^{[20]}$

In summary, compartmentalization in water from emulsion processes (with or without the presence of surfactant) is a very promising way to produce high molecular weight polyethylenes in the low to very low density range by FRP under mild conditions from a water soluble cationic initiator. PE yields are higher than for the solvent processes previously developed. From a colloidal point of view, FRP in emulsion exhibits unexpected original behaviors. In the presence of surfactant, very small PE cylinder particles are generated while larger quasi-spherical particles were formed in the surfactant-free process. Investigations of the coating properties of these attractive PE nanoparticles are in progress.

The experimental details are provided in the Supporting Information part.

Keywords: nanoparticles · polymerization · free radical polymerization $\cdot$ polyethylene $\cdot$ emulsion

[1] R. Mulhaupt, Macromol. Chem. Phys. 2003, 204, 289-327.

[2] D.L. Beach, Y.V. Kissin, in Encyclopedia of Polymer Science and Engineering, 2nd ed., Vol. 6 (Eds: H.F. Mark, N. M. Bikales, C. G.
Overberger, G. Menges), WILEY INTERSCIENCE, New York, 1985, pp 454-489.

[3] K.W. Doak, in Encyclopedia of Polymer Science and Engineering, 2nd ed., Vol. 6 (Eds: H.F. Mark, N. M. Bikales, C. G. Overberger, G. Menges), WILEY INTERSCIENCE, New York, 1985, pp 386-428.

[4] S.L. Aggarwal, O.J. Sweeting, Chem. Rev. 1957, 57, 665-742.

[5] S P. Ehrlich, G. A. Mortimer, Adv. Polymer Sci., 1970, 7, 386-448.

[6] M. Kemmere, T. de Vries, M. Vorstman, J. Keurentjes, Chem. Eng. Sc. 2001, 56, 4197-4204.

[7] A. Bastero, G. Francio, W. Leitner, S. Mecking, Chem. Eur. J. 2006, 12, 6110-6116.

[8] L. Kolb, V. Monteil, R. Thomann, S. Mecking, Angew. Chem. 2005, 117, 433-436.

[9] A. Held, F.M. Bauers, S. Mecking, Chem. Comm. 2000, 301-302

[10] R. Soula, C. Novat, A. Tomov, R. Spitz, J. Claverie, X. Drujon, J. Malinge, T. Saudemont, Macromolecules 2001, 34, 2022-2026.

[11] S. Mecking, Coll. Polym. Sci. 2007, 285, 605-619.

[12] E. Grau, J.P. Broyer, C. Boisson, R. Spitz, V. Monteil, Macromolecules 2009, 42, 7279-7281.

[13] H. Hopff, R. Kern, Modern Plastics 1946, 153-220.

[14] A.F. Helin, H.K. Stryker, G.J. Mantell, J. App. Polym. Sc. 1965, 9, 1797-1805.

[15] A.F. Helin, H.K. Stryker, G.J. Mantell, J. App. Polym. Sc. 1965, 9, $1807-1822$

[16] T. Suwa, H. Nakajima, M. Takehisa, S. Machi, Polym. Let. Ed. 1975, 13, 369-375.

[17] H.K. Stryker, G.J. Mantell, J. Polym Sci. C Polym. Symp. 1969, 27, $35-48$.

[18] G.B. Galland, R.F. de Souza, R.S. Mauler, F.F. Nunes, Macromolecules 1999, 32, 1620-1625.

[19] F.M. Bauers, R. Thomann, S. Mecking, J. Am. Chem. Soc. 2003, 125, 8838-8840.

[20] High PI can also be partially due to a wide distribution in cylinder thickness. 
Entry for the Table of Contents (Please choose one layout)

Layout 1:

\section{Polyethylene Nanoparticles}

E. Grau, P.-Y. Dugas, J.-P. Broyer, C. Boisson, R. Spitz, V. Monteil

Page - Page

Aqueous Dispersions of Non Spherical Polyethylene Nanoparticles from Free Radical Polymerization under Mild Conditions
Stable PE Nanoparticles Dispersions

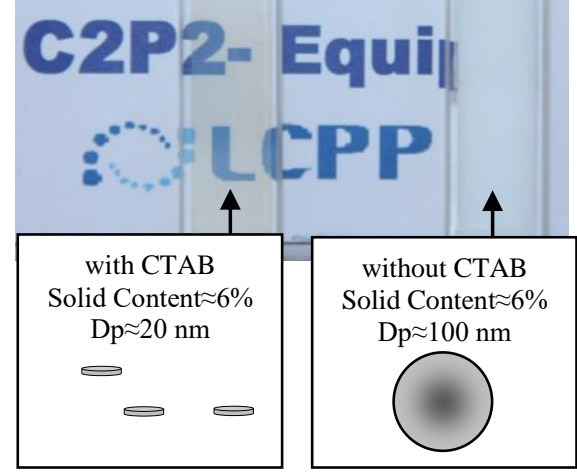

Free radical polymerizations of ethylene usually require severe conditions. We investigate the efficiency of this reaction under mild conditions ( $<250$ bar) in water in order to produce PE stable aqueous dispersions. Latexes of PE nanoparticles with various shapes (cylinder or sphere) and solid contents up to $40 \%$ were prepared. 


\section{Supporting Information}

Table of Content :

$\begin{array}{ll}\text { Experimental Section } & \text { S2 }\end{array}$

Figure S1 : Typical ${ }^{13} \mathrm{C}$ NMR of polyethylene prepared in water $\quad$ S4

Figure S2 : Typical ${ }^{13} \mathrm{C}$ NMR of polyethylene prepared in water/THF

Figure S3 : TEM picture of PE latex before (a) and and after $4 \mathrm{~h}$ at $70^{\circ} \mathrm{C}$ and additional CTAB (b)

Table S1: Influence of ethylene pressure on free radical polymerization of ethylene in aqueous dispersed medium

Table S2 : Influence of additional organic solvent on free radical polymerization of ethylene in aqueous dispersed medium

S8

Table S3 : Influence of polymerization time on free radical polymerization of ethylene in aqueous dispersed medium 


\section{Experimental section}

All chemicals were purified using standard Schlenk procedures and handled under argon atmosphere. Solvents (THF and toluene) were distilled or degassed under argon. Water was purified using Milli-Q academic system (Millipore Corporation) and degassed under argon. Ethylene (purity 99.95\%) was purchased from Air Liquide, AIBA and CTAB from Acros and used without any further purification.

\section{Latex characterizations}

Particle size was determined by dynamic light scattering (DLS) using a Malvern Zetasizer $1000 \mathrm{HAS}$ autosizer apparatus with a detection angle of $90^{\circ}$ at $25^{\circ} \mathrm{C}$. The measurements were performed on highly diluted samples in order to rule out interaction and multiple scattering effects. The intensity average diameter was computed from the intensity autocorrelation data using the cumulant analysis method. The final data was the average of 5 measurements for each sample. TEM analysis was performed after placing a drop of the particle suspension on a copper grid (3.05mm copper grid with Formvar/Carbon support Film, 200 mesh (Agar Scientific)) and dried before analysis. TEM was performed in a Philips CM120 transmission electron microscope, at an acceleration voltage of $80 \mathrm{kV}$ (Centre Technologique des Microstructures $(\mathrm{CT} \mu)$ - Plateforme d'Imagerie Integrative $\left(\mathrm{PI}^{2}\right)$, Claude Bernard University, Lyon, France).

\section{Polymer characterizations}

Molecular weights of polyethylenes were determined by size exclusion chromatography (SEC) using a Waters Alliance GPCV 2000 instrument (columns: PLgel Olexis); two detectors (viscosimeter and refractometer) in trichlorobenzene (flow rate: $1 \mathrm{~mL} / \mathrm{min}$ ) at $150^{\circ} \mathrm{C}$. The system was calibrated with polystyrene standards using universal calibration. Differential scanning calorimetry (DSC) was performed on a Mettler Toledo DSC1 at a 
heating rate of $5 \mathrm{~K} / \mathrm{min}$. Two successive heating and cooling of samples were performed. We have considered data (Tm values, crystallinity) obtained during the second heats. Highresolution liquid NMR spectroscopy was carried out with a Bruker DRX 250 spectrometers operating at $250 \mathrm{MHz}$ for ${ }^{1} \mathrm{H}$. Spectra were obtained with a 5-mm QNP probe. PE samples were examined as $10-15 \%(\mathrm{w} / \mathrm{v})$ solutions using a mixture of tetrachloroethylene (TCE) and perdeuterobenzene $\left(\mathrm{C}_{6} \mathrm{D}_{6}\right)(2 / 1 \mathrm{v} / \mathrm{v})$ as solvent at $363 \mathrm{~K}$. Chemical shift values $(\delta)$ are given in ppm in reference to internal tetramethylsilane (TMS).

\section{Standard polymerization procedure}

Caution, all polymerizations involve high pressure and explosive gaz.

Ethylene polymerizations were done in a $160 \mathrm{~mL}$ stainless steel autoclave (equipped with safety valves, stirrer, oven) from Parr Instrument Co.. The 2,2-azobis(2amidinopropane)dihydrochloride (AIBA) was dissolved in the desired volume of water (or a solution of cetyltrimethylammonium bromide $(\mathrm{CTAB})$ at $1 \mathrm{~g} / \mathrm{L})$ in a Schlenk tube under argon. The mixture was introduced through cannula into the reactor. Ethylene was introduced and the mixture was heated at the desired temperature under stirring (250 rpm). To manage safely polymerization over 50 bar of ethylene we use a $1.5 \mathrm{~L}$ intermediate tank. The tank was cooled down to $-20^{\circ} \mathrm{C}$ to liquefy ethylene at 35 bar. When thermodynamic equilibrium was reached, the intermediate tank was isolated and heated to reach up to a pressure of 300 bar. This tank was used to charge the reactor. After 4 hours of polymerization the reactor was slowly cooled down and degassed. A stable dispersion of polyethylene nanoparticles was obtained. A fraction of the latex was then dried under vacuum at $70^{\circ} \mathrm{C}$ to determine solid content. Polymer analyses (by NMR, DSC, SEC) were performed on dried samples washed with water. 


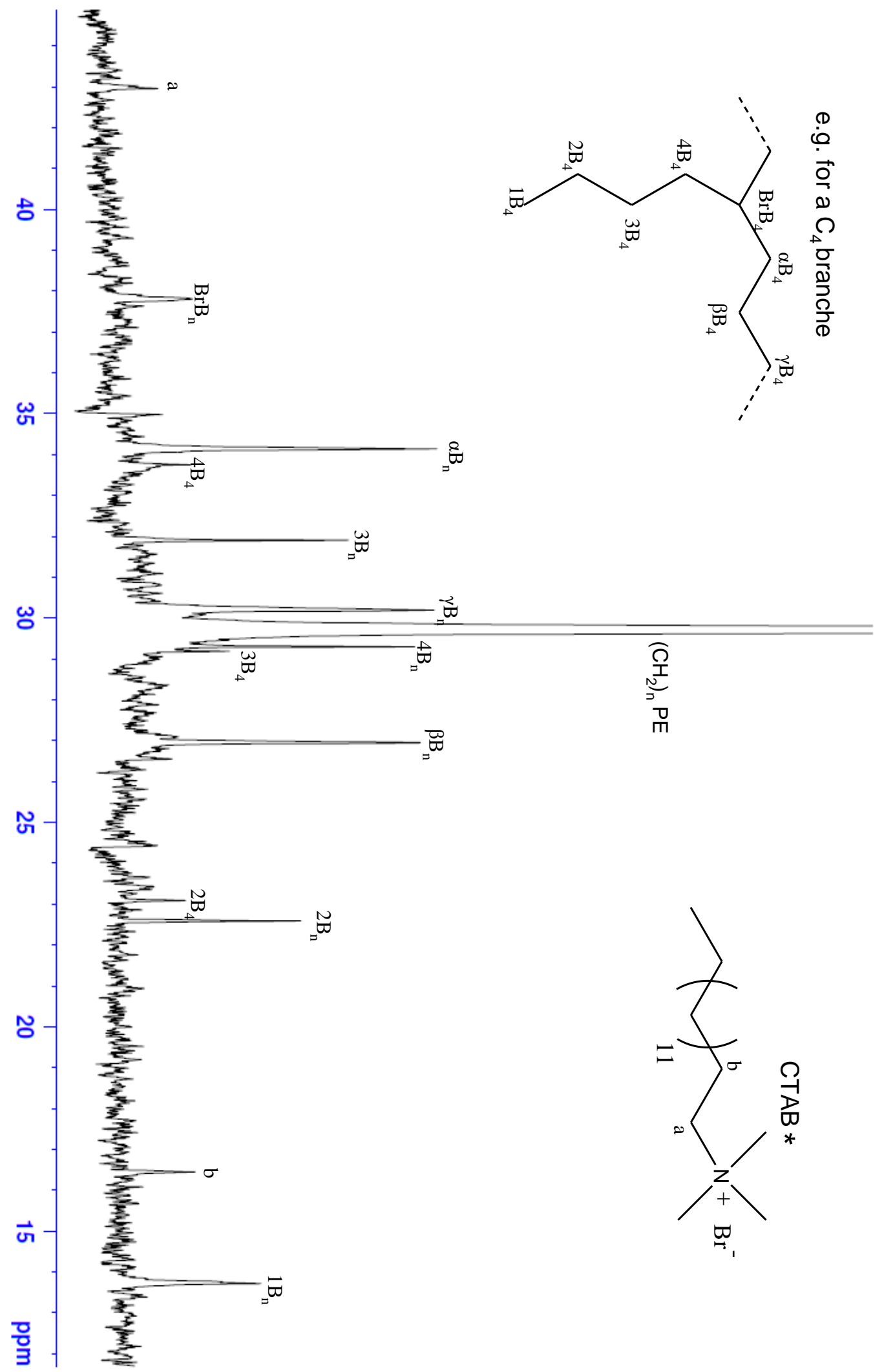

Figure S1: Typical ${ }^{13} \mathrm{C}$ NMR of polyethylene prepared in water (notation from Galland et al ref 18 of the article) * a, b signals are representative of CTAB. The presence of CTAB can be explained by two different hypotheses: CTAB is linked to PE after transfer to surfactant or has cocrystallized with PE. 


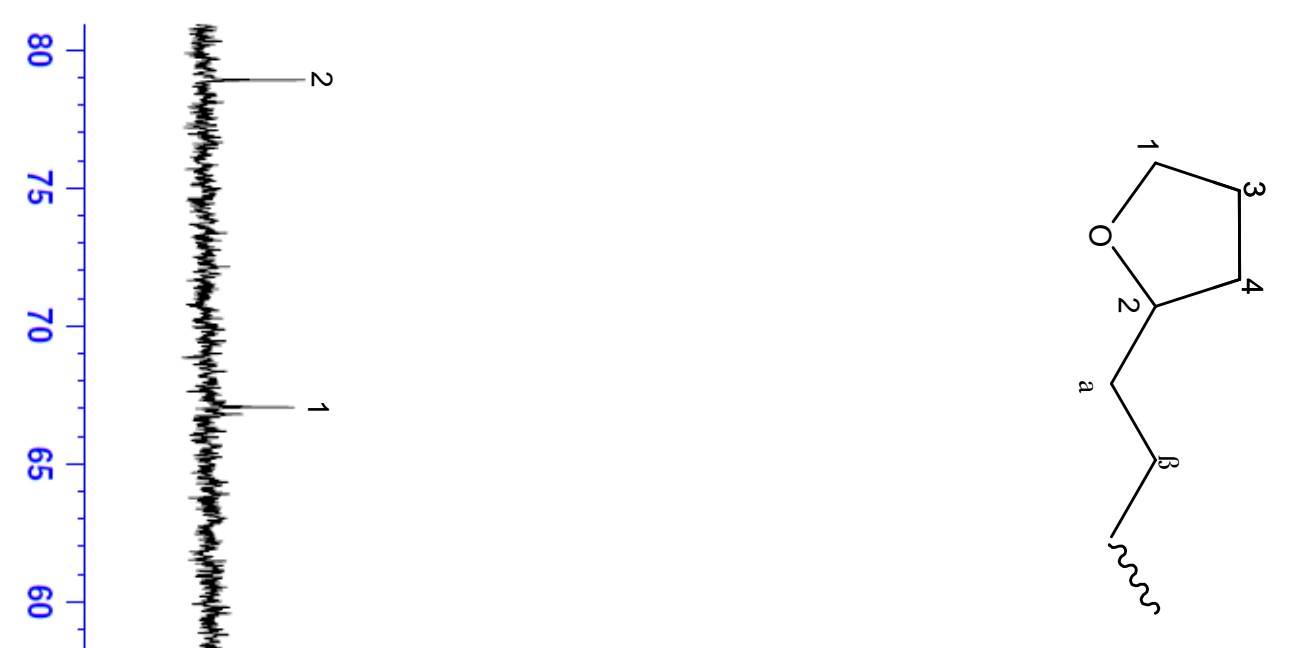




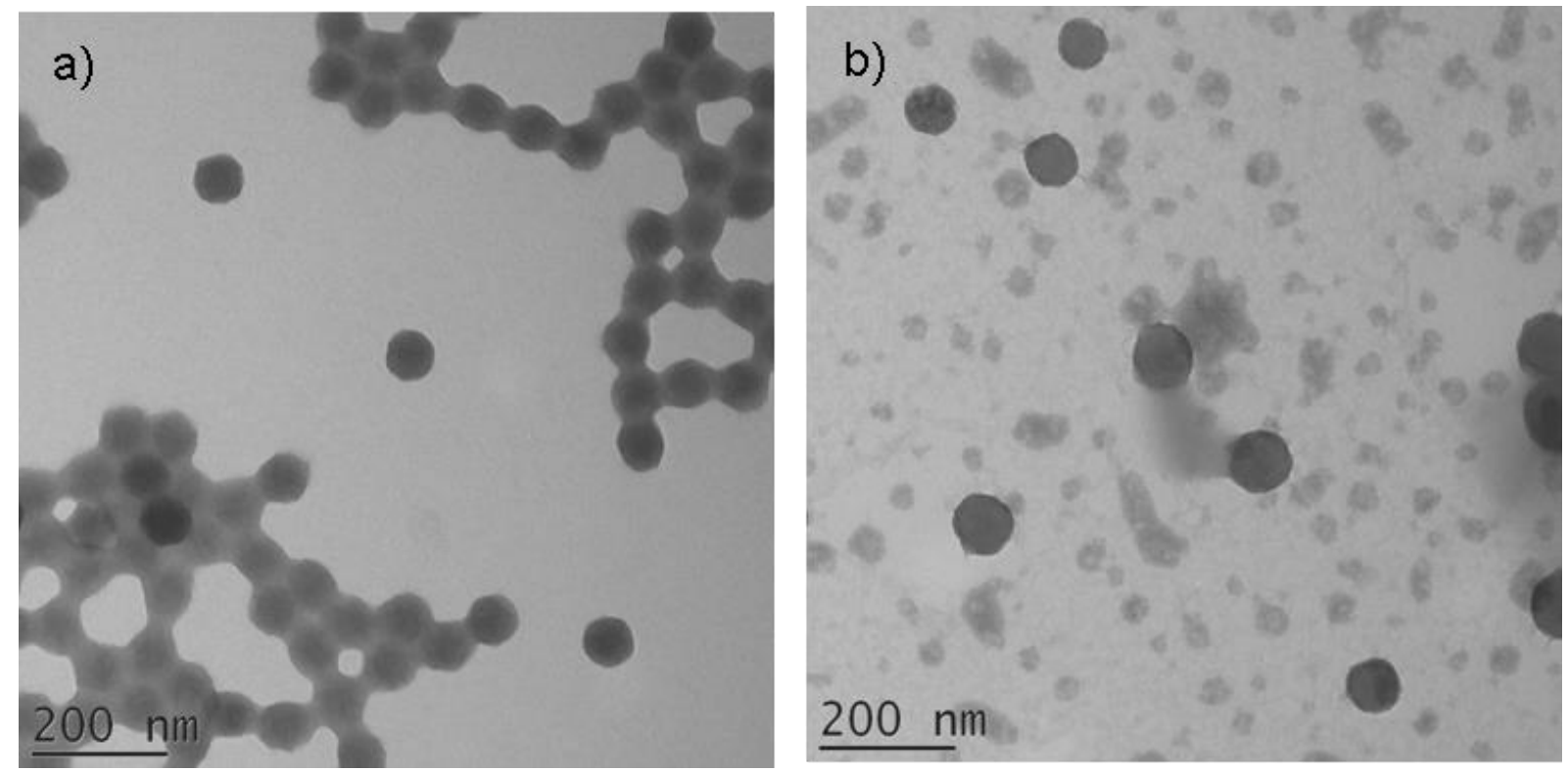

Figure S3: TEM picture of PE latex before (a) and after $4 \mathrm{~h}$ at $70^{\circ} \mathrm{C}$ and additional CTAB (b) 
Table S1: Influence of ethylene pressure on free radical polymerization of ethylene in aqueous dispersed medium ${ }^{\mathrm{a}}$ (experimental data of Figure 1)

\begin{tabular}{|c|c|c|c|c|c|c|c|c|c|}
\hline Run & $\begin{array}{c}\text { Ethylene } \\
\text { Pressure } \\
\text { (bar) }\end{array}$ & $\begin{array}{c}\text { CTAB } \\
(\mathrm{g} / \mathrm{L})\end{array}$ & $\begin{array}{l}\text { Yield } \\
\text { (g) }\end{array}$ & $\begin{array}{c}\text { Melting } \\
\text { point } \\
\left({ }^{\circ} \mathrm{C}\right)^{b}\end{array}$ & $\begin{array}{c}\text { Crystallinity } \\
(\%)^{b}\end{array}$ & $\begin{array}{c}\text { Mn } \\
(\mathrm{g} / \mathrm{mol})^{\mathrm{c}}\end{array}$ & PDI $^{\mathrm{c}}$ & $\begin{array}{c}\text { Dp } \\
(n m)^{d}\end{array}$ & $\mathbf{P I}^{\mathrm{d}}$ \\
\hline 1 & 50 & 0 & 0.3 & 70.3 & 12 & 10800 & 3.4 & $\begin{array}{c}32 \\
( \pm 2)\end{array}$ & $\begin{array}{c}0.07 \\
( \pm 0.01)\end{array}$ \\
\hline 2 & 100 & 0 & 1.3 & 96.5 & 35 & 21600 & 6.0 & $\begin{array}{c}89 \\
( \pm 1)\end{array}$ & $\begin{array}{c}0.04 \\
( \pm 0.01)\end{array}$ \\
\hline 3 & 150 & 0 & 1.8 & 100.9 & 30 & 31100 & 7.3 & $\begin{array}{l}104 \\
( \pm 1)\end{array}$ & $\begin{array}{c}0.06 \\
( \pm 0.03)\end{array}$ \\
\hline 4 & 200 & 0 & 2.2 & 106.0 & 40 & 20800 & 6.1 & $\begin{array}{l}109 \\
( \pm 1)\end{array}$ & $\begin{array}{c}0.03 \\
( \pm 0.01)\end{array}$ \\
\hline 5 & 250 & 0 & 2.5 & 104.6 & 37 & 21000 & 7.9 & $\begin{array}{l}113 \\
( \pm 1)\end{array}$ & $\begin{array}{c}0.03 \\
( \pm 0.02)\end{array}$ \\
\hline 6 & 50 & 1 & 0.7 & 69.5 & 10 & 38800 & 2.8 & $\begin{array}{c}97 \\
( \pm 3)\end{array}$ & $\begin{array}{c}0.71 \\
( \pm 0.03)\end{array}$ \\
\hline 7 & 100 & 1 & 4.6 & 92.8 & 31 & 50500 & 8.7 & $\begin{array}{c}24 \\
( \pm 1)\end{array}$ & $\begin{array}{c}0.52 \\
( \pm 0.08)\end{array}$ \\
\hline 8 & 150 & 1 & 7.9 & 97.3 & 31 & 60500 & 7.4 & $\begin{array}{c}51 \\
( \pm 1)\end{array}$ & $\begin{array}{c}0.17 \\
( \pm 0.02)\end{array}$ \\
\hline 9 & 200 & 1 & 12.3 & 99.4 & 29 & 73800 & 8.1 & $\begin{array}{c}52 \\
( \pm 1)\end{array}$ & $\begin{array}{c}0.22 \\
( \pm 0.02)\end{array}$ \\
\hline 10 & 250 & 1 & 19.9 & 97.0 & 31 & 119000 & 6.3 & $\begin{array}{c}46 \\
( \pm 2)\end{array}$ & $\begin{array}{c}0.33 \\
( \pm 0.09)\end{array}$ \\
\hline
\end{tabular}

${ }^{\text {a }}$ Reactions were carried out at $70^{\circ} \mathrm{C}$ under ethylene pressure during $4 \mathrm{~h}$ with $80 \mathrm{mg}$ AIBA in $50 \mathrm{~mL}$ of water; ${ }^{\mathrm{b}}$ determined by DSC, ${ }^{\mathrm{c}}$ dertermined by HTSEC, ${ }^{\mathrm{d}}$ determined by DLS 
Table S2: Influence of additional organic solvent on free radical polymerization of ethylene in aqueous dispersed medium ${ }^{\mathrm{a}}$

\begin{tabular}{|c|c|c|c|c|c|c|c|c|c|}
\hline Run & $\begin{array}{c}\text { Water } \\
(\mathrm{mL}) / \\
\text { Solvent } \\
(\mathrm{mL}) \\
\text { [solvent] }\end{array}$ & $\begin{array}{c}\text { CTAB } \\
(\mathrm{g} / \mathrm{L})\end{array}$ & $\begin{array}{l}\text { Yield } \\
\text { (g) }\end{array}$ & $\begin{array}{c}\text { Melting } \\
\text { point } \\
\left({ }^{\circ} \mathrm{C}\right)^{\mathrm{c}}\end{array}$ & $\begin{array}{c}\text { Crystallinity } \\
(\%)^{\mathrm{c}}\end{array}$ & $\begin{array}{c}\text { Mn } \\
(\mathrm{g} / \mathrm{mol})^{d}\end{array}$ & PDI $^{\mathbf{d}}$ & $\begin{array}{c}\text { Dp } \\
(\mathbf{n m})^{\mathrm{e}}\end{array}$ & $\mathbf{P I}^{\mathrm{e}}$ \\
\hline $\begin{array}{c}11 \\
(=2)\end{array}$ & $50 / 0$ & 0 & 1.3 & 96.5 & 35 & 21600 & 6.0 & $\begin{array}{c}89 \\
( \pm 1)\end{array}$ & $\begin{array}{c}0.04 \\
( \pm 0.01)\end{array}$ \\
\hline $\begin{array}{c}12 \\
(=7)\end{array}$ & $50 / 0$ & 1 & 4.6 & 92.8 & 31 & 50500 & 8.7 & $\begin{array}{c}24 \\
( \pm 1)\end{array}$ & $\begin{array}{c}0.52 \\
( \pm 0.08)\end{array}$ \\
\hline $13^{\mathrm{b}}$ & 0/50 [THF] & 0 & 3.9 & 115.2 & 58 & 1190 & 1.9 & & \\
\hline 14 & $\begin{array}{l}40 / 10 \\
{[\mathrm{THF}]}\end{array}$ & 0 & 1.3 & 105.0 & 44 & 1760 & 3.8 & $\begin{array}{l}129 \\
( \pm 2)\end{array}$ & $\begin{array}{c}0.03 \\
( \pm 0.02)\end{array}$ \\
\hline 15 & $\begin{array}{l}40 / 10 \\
{[\mathrm{THF}]}\end{array}$ & 1 & 3.2 & 103.1 & 40 & 2350 & 3.2 & $\begin{array}{c}16 \\
( \pm 1)\end{array}$ & $\begin{array}{c}0.39 \\
( \pm 0.07)\end{array}$ \\
\hline $16^{\mathrm{b}}$ & $\begin{array}{c}0 / 50 \\
\text { [toluene] }\end{array}$ & 0 & 0.7 & 115.9 & 63 & 2340 & 1.9 & & \\
\hline 17 & $\begin{array}{c}40 / 10 \\
\text { [toluene] }\end{array}$ & 0 & 0.4 & 104.5 & 27 & 17100 & 2.6 & $\begin{array}{c}72 \\
( \pm 5)\end{array}$ & $\begin{array}{c}0.14 \\
( \pm 0.06)\end{array}$ \\
\hline 18 & $\begin{array}{c}40 / 10 \\
\text { [toluene] }\end{array}$ & 1 & 0.8 & 99.9 & 22 & 8300 & 3.2 & $\begin{array}{c}121 \\
( \pm 32)\end{array}$ & $\begin{array}{c}0.88 \\
( \pm 0.11)\end{array}$ \\
\hline
\end{tabular}

${ }^{\mathrm{a}}$ Reactions were carried at $70^{\circ} \mathrm{C}$ under 100 bar ethylene pressure during $4 \mathrm{~h}$ with $80 \mathrm{mg}$ AIBA in $50 \mathrm{~mL}$ of solvent; ${ }^{b}$ In organic medium iniator is $50 \mathrm{mg}$ of AIBN because AIBA is not soluble in this solvent see E. Grau, J.P. Broyer, C. Boisson, R. Spitz, V. Monteil, Macromolecules 2009, 42, 7279-7281, ${ }^{\mathrm{c}}$ determined by DSC, ${ }^{\mathrm{d}}$ dertermined by HTSEC, ${ }^{\mathrm{e}}$ determined by DLS 
Table S3 : Influence of polymerization time on free radical polymerization of ethylene in aqueous dispersed medium ${ }^{\mathrm{a}}$ (experimental data of Figure 2)

\begin{tabular}{|c|c|c|c|c|c|c|c|c|c|}
\hline Run & Time (h) & $\begin{array}{c}\text { CTAB } \\
(\mathrm{g} / \mathrm{L})\end{array}$ & $\begin{array}{l}\text { Yield } \\
\text { (g) }\end{array}$ & $\begin{array}{c}\text { Melting } \\
\text { point } \\
\left({ }^{\circ} \mathrm{C}\right)^{b}\end{array}$ & $\begin{array}{c}\text { Crystallinity } \\
(\%)^{\mathbf{b}}\end{array}$ & $\begin{array}{c}\text { Mn } \\
(\mathrm{g} / \mathrm{mol})^{\mathrm{c}}\end{array}$ & PDI $^{\mathbf{c}}$ & $\begin{array}{c}D p \\
(n m)^{d}\end{array}$ & $\mathbf{P I}^{\mathbf{d}}$ \\
\hline 19 & 0.25 & 0 & 0.1 & 97.6 & 13 & nd & nd & $\begin{array}{c}29 \\
( \pm 1)\end{array}$ & $\begin{array}{c}0.04 \\
( \pm 0.01)\end{array}$ \\
\hline 20 & 0.5 & 0 & 0.3 & 99.3 & 16 & nd & nd & $\begin{array}{c}46 \\
( \pm 1)\end{array}$ & $\begin{array}{c}0.04 \\
( \pm 0.02)\end{array}$ \\
\hline 21 & 1 & 0 & 0.5 & 94.8 & 19 & 319700 & 6.2 & $\begin{array}{c}57 \\
( \pm 1)\end{array}$ & $\begin{array}{c}0.05 \\
( \pm 0.01)\end{array}$ \\
\hline 22 & 2 & 0 & 0.7 & 96.3 & 24 & 74100 & 4.8 & $\begin{array}{c}76 \\
( \pm 1)\end{array}$ & $\begin{array}{c}0.03 \\
( \pm 0.03)\end{array}$ \\
\hline $\begin{array}{c}23 \\
(=2)\end{array}$ & 4 & 0 & 1.3 & 96.5 & 35 & 21600 & 6.0 & $\begin{array}{c}89 \\
( \pm 1)\end{array}$ & $\begin{array}{c}0.04 \\
( \pm 0.01)\end{array}$ \\
\hline 24 & 14 & 0 & 2.4 & 97.7 & 36 & 30500 & 5.4 & $\begin{array}{l}122 \\
( \pm 2)\end{array}$ & $\begin{array}{c}0.02 \\
( \pm 0.02)\end{array}$ \\
\hline 25 & 0.25 & 1 & 0.2 & 91.4 & 15 & 55400 & 4.0 & $\begin{array}{l}106 \\
( \pm 6)\end{array}$ & $\begin{array}{c}0.82 \\
( \pm 0.11)\end{array}$ \\
\hline 26 & 0.5 & 1 & 0.6 & 94.0 & 21 & 22400 & 7.3 & $\begin{array}{l}121 \\
( \pm 3)\end{array}$ & $\begin{array}{c}0.91 \\
( \pm 0.02)\end{array}$ \\
\hline 27 & 1 & 1 & 1.2 & 88.2 & 23 & 107400 & 5.6 & $\begin{array}{c}37 \\
( \pm 3)\end{array}$ & $\begin{array}{c}0.52 \\
( \pm 0.03)\end{array}$ \\
\hline 28 & 2 & 1 & 2.5 & 89.0 & 25 & 54200 & 7.7 & $\begin{array}{c}28 \\
( \pm 1)\end{array}$ & $\begin{array}{c}0.52 \\
( \pm 0.06)\end{array}$ \\
\hline $\begin{array}{l}29 \\
(=7)\end{array}$ & 4 & 1 & 4.6 & 92.8 & 31 & 50500 & 8.7 & $\begin{array}{c}24 \\
( \pm 1)\end{array}$ & $\begin{array}{c}0.52 \\
( \pm 0.08)\end{array}$ \\
\hline 30 & 14 & 1 & 6 & 91.1 & 30 & 43900 & 5.7 & $\begin{array}{c}19 \\
( \pm 1)\end{array}$ & $\begin{array}{c}0.48 \\
( \pm 0.01)\end{array}$ \\
\hline
\end{tabular}

${ }^{\text {a }}$ Reactions were carried at $70^{\circ} \mathrm{C}$ under 100 bar of ethylene with $80 \mathrm{mg}$ AIBA in $50 \mathrm{~mL}$ of water; ${ }^{b}$ determined by DSC, ${ }^{c}$ dertermined by HTSEC, ${ }^{d}$ determined by DLS, nd not determined 